\title{
Tumores testiculares na infância
}

\section{Testicular tumors in childhood}

Roni Leonardo Teixeira, TCBC - MT¹; Aírton Rossinı; Neiva Pereira Paim³

\section{INTRODUÇÃO}

$A^{s}$ neoplasias representam mais de $20 \%$ de todas as doenças testiculares e paratesticulares na infância, mesmo assim são raros, constituindo $1 \%$ do total de tumores sólidos pediátricos, com uma incidência anual de 0,5 a 2/100000 meninos. Estes tumores se subdividem em dois grupos: tumores de células germinativas e tumores de células não germinativas, podendo ocorrer em todas as idades, mas com dois picos de ocorrência, antes dos três anos de idade e no período pós puberal, dos quais cerca de $75 \%$ dos tumores, são malignos, e cerca de 19\% destes apresentam metástases ${ }^{1}$.

Estes tumores apresentam características biológicas específicas, que se diferenciam das neoplasias testiculares em adultos, devendo assim, serem estudados à parte. Com isso, cinco aspectos devem ser levados em consideração ${ }^{2}$ : 1 - Nos adultos, tumores de células não germinativas testiculares são raros, enquanto, entre os meninos, é uma patologia comum, em torno de 25 a 40\%; 2 - Seminomas e coriocarcinomas não ocorrem na infância e, por isso, a freqüência relativa dos diversos tipos de tumores germinativos difere da observada nos adultos Os tumores de células germinativas representam 60 a $75 \%$ dos tumores testiculares na infância, tendo como principal exemplo o tumor de saco vitelínico (ou tumor do seio endodérmico) (65\% das neoplasias), seguido pelos teratomas (14\%); apesar de existirem alguns trabalhos em que o teratoma, se apresenta como o mais comum ${ }^{3,4}$. 3 - Algumas vezes, o tumor de saco vitelínico é confundido com o carcinoma embrionário do adulto, no entanto, aquele possui melhor prognóstico, por se apresentar como doença localizada freqüentemente; 4 - Teratomas são considerados doenças benignas, com raros relatos de metástases; 5 - Cerca de 10\% dos tumores testiculares são identificados no período neonatal e, neste grupo particular, aproximadamente $2 / 3$ dos casos são representados pelos tumores do estroma gonadal. Lembrando que a forma mais comum de apresentação clínica é de massa testicular indolor ${ }^{1}$ (Figura 1). A Seção de Urologia da Associação Americana de Pediatria propôs uma classificação para os tumores testiculares na infância (Tabela 1). Recomenda-se a utilização do estadiamento, segundo o Pediatric Oncology Group (POG) e o Children's Câncer Group (CCG) ${ }^{5,6}$ (Tabela 2)

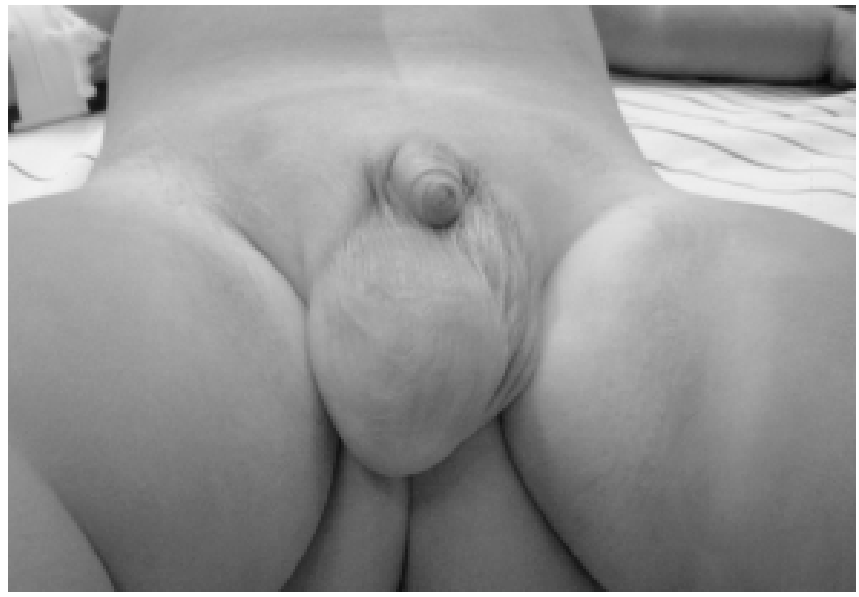

Figura 1 - Tumor de testículo direito, em menino de 1 ano de idade.

Tabela 1 - Classificação dos tumores testiculares prépuberais.

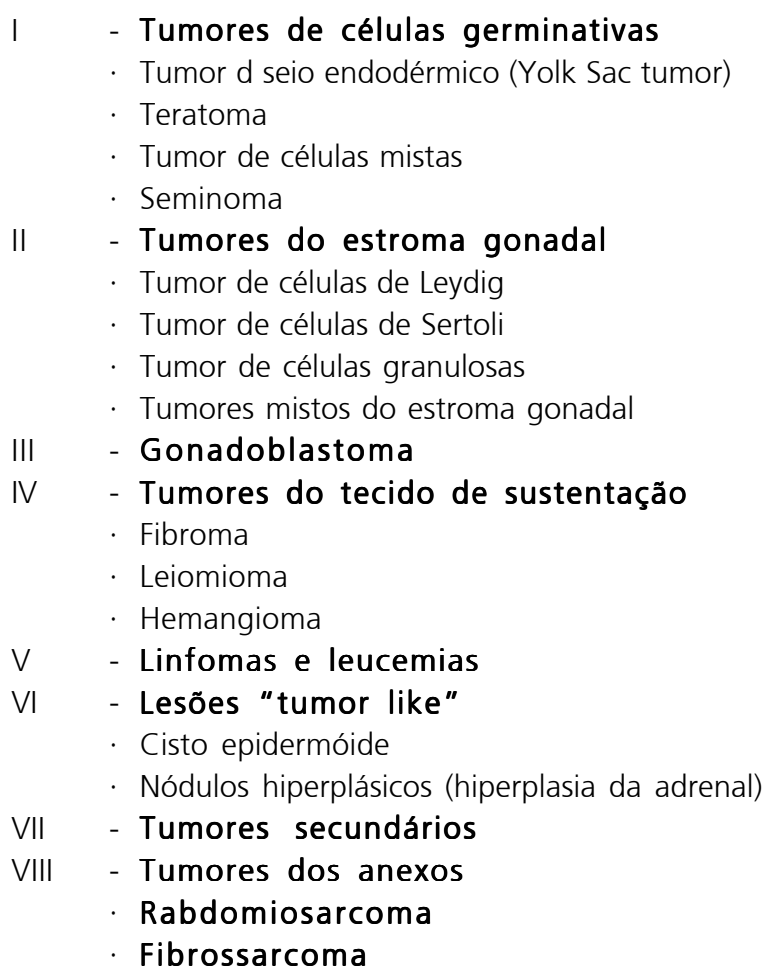

Trabalho realizado no Serviço de Cirurgia Pediátrica da Fundação Comunitária de Saúde de Sinop - MT, BR.

1. Cirurgião Pediátrico e Chefe do Serviço de Cirurgia Pediátrica da Fundação Comunitária de Saúde de Sinop - MT, BR; 2. Cirurgião Oncológico e Diretor do Serviço de Oncologia da Fundação Comunitária de Saúde de Sinop - MT, BR; 3. Médica Patologista e Chefe do Laboratório de Anatomia Patológica Luigi Bogliolo - Sinop - MT, BR. 
Tabela 2 - Estadiamento dos tumores testiculares na infância, segundo o Pediatric Oncology Group (POG) e o Children's Câncer Group (CCG).

\begin{tabular}{|c|c|}
\hline Estadio & Extensão do Tumor \\
\hline \multirow[t]{4}{*}{ I } & - limitado ao testículo \\
\hline & - Ressecção tumoral completa sem disseminação \\
\hline & - Sem evidência radiológica e patológica de extensão \\
\hline & - Marcadores ou biópsia retroperitoneal negativa \\
\hline \multirow[t]{4}{*}{ II } & - Disseminação macroscópica do tumor na cirurgia; \\
\hline & - Doença residual microscópica no escroto ou no cordão \\
\hline & - $\quad$ Adenopatias retroperitoneais menores de 2 cm; \\
\hline & - Aumento de marcadores tumorais, antes diminuídos \\
\hline III & - Adenopatias retroperitoneais maiores que $5 \mathrm{~cm}$ \\
\hline IV & - Metástases à distância \\
\hline
\end{tabular}

\section{TUMOR DE SEIO ENDODÉRMICO (TUMOR DO SACO VITELINNICO - "YOLK SAC TUMOR")}

O tumor de seio endodérmico é o tumor de células germinativas mais recentemente reconhecido. Foi descrito por Schiller, em 1939, no ovário e designado mesonefroma ${ }^{7}$. Também conhecido como tumor do saco vitelínico, tumor de Teilum ou orquioblastoma, é raro na prática clínica, porém é o mais comum tumor maligno testicular na infância, cerca de 70 a 80 \% do total.

Clinicamente, há um aumento assintomático do testículo acometido, normalmente, antes dos dois anos de idade podendo ter hidrocele associada a alguns casos (15 a $25 \%)$, o que, muitas vezes pode retardar o diagnóstico. 0 testículo afetado adota uma posição mais baixa e verticalizada em relação ao testículo normal contralateral. ${ }^{2,8}$

O aspecto histopatológico destes tumores é muito variado, com formação de microcistos, macrocistos, áreas sólidas, glandular-alveolar, mixomatoso, sarcomatóide, hepatóide, entre outros. $O$ aspecto característico é a diferenciação em seio endodérmico representado pelos corpúsculos de Schiller-Duval (Figura 2). O exame ultra-sonográfico, mostra uma massa sólida, hipervascularizada, com focos hemorrágicos. A dosagem de alfafetoproteína (AFP) é mandatória para investigação de tumor do seio endodérmico, aumentado em cerca de $80 \%$ destes pacientes, devido a produção deste marcador por células do seio endodérmico, mimetizando a produção fisiológica da AFP do início da embriogênese. A ultrassonografia apenas, não é específica para o diagnóstico do tumor de seio endodérmico, no entanto, sua associação com a dosagem sanguínea de altos níveis de AFP , faz com que, este diagnóstico deva ser considerado em meninos com massa testicular 7,8,10.

Aproximadamente $80 \%$ destes tumores estão confinados ao testículo (estádio I). O tratamento é a orquiectomia, com abordagem via inguinal, devido à possibilidade de disseminação hematogênica, pela abordagem escrotal, necessitando de isolamento e ligadura atraumática precoce do cordão espermático e, posteriormente, proceder à orquiectomia (Figura 3). O papel da linfadenectomia retroperitoneal é controversa, existindo alguns aspectos deste tumor que não justificam a realização deste tipo de operação: tumor com tendência por disseminação via hematogênica, com comprometimento pulmonar em 20\% dos casos; com invasão linfática retroperitoneal somente em 4 - 5\% dos pacientes; a maioria dos tumores do seio endodérmico são tumores puros; Em torno de $85 \%$ destes

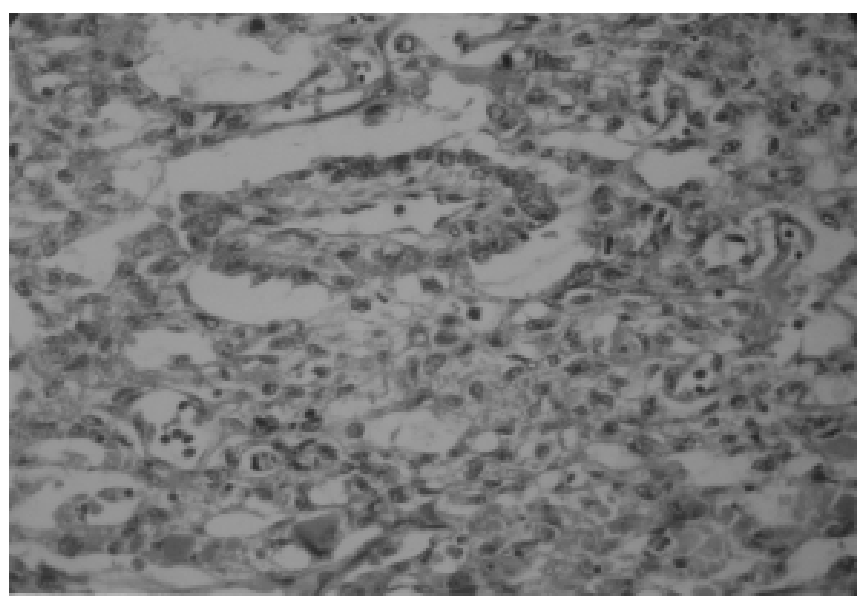

Figura 2 - Corpúsculo de Schiller- Duval, oservado no tumor do seio endodérmico.

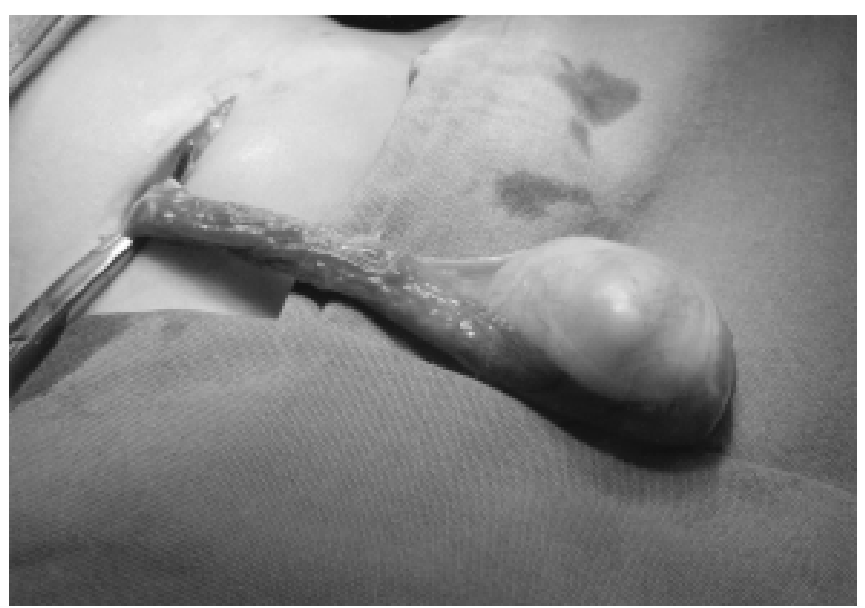

Figura 3 - Abordagem inguinal para orquiectomia de tumor testicular. 
pacientes encontram-se em estádio I. Assim a linfadenectomia retroperitoneal, não influencia no prognóstico ou curso da doença, aumentando sua morbidade 5,6,11.

O seguimento destes pacientes é feito com dosagens de AFP e radiografias de tórax realizadas mensalmente, tomografias computadorizadas abdominais realizadas trimestralmente no primeiro ano. Após o primeiro ano se não houver alterações, a AFP e a radiografia torácica serão realizadas de $2 / 2$ meses e a tomografia semestralmente até completar dois anos de seguimento do paciente. A partir de então estes serão exames serão realizados anualmente. Os pacientes em estádios II, III, IV, são submetidos a quimioterapia e posterior orquiectomia com linfadenectomia retroperitoneal 5, 6,12 .

\section{TERATOMAS}

É o segundo tumor testicular mais freqüente na infância, variando de 13 a $60 \% \%^{5,13}$. O tumor do seio endodérmico tem uma maior divulgação, conseqüentemente, uma maior incidência, porém algumas instituições e serviços, acreditam que, atualmente, o teratoma possa ser o mais comum tumor primário testicular na infância ${ }^{14-17}$.A verdadeira incidência é desconhecida, em parte, devido a baixa divulgação de tumores testiculares benignos $^{13}$. Ao exame ultrassonográfico mostra áreas císticas com septação, permeadas com áreas sólidas, a grande maioria dos tumores testiculares são sólidas, à exceção do tumor de célula granulosa, o qual é extremamente raro. A presença de calcificações, que normalmente reapresenta tecido ósseo ou corpo psamoma, é outro dado que auxilia no diagnóstico, encontrado nos teratomas. Os níveis de AFP, pode nos ajudar na diferenciação entre tumores do seio endodérmico, encontrando-se alterados, nestes em até 93\% dos casos.Lembrando que, fisiologicamente, os níveis de AFP, pode estar elevado até aproximadamente oito meses de vida ${ }^{13}$. São tumores encapsulados, podendo conter cistos de tamanhos variados, além de diversos tipos de tecidos, como osso, músculo, cartilagem etc.

Em indivíduos pré púberes o teratoma tem comportamento benigno, no entanto, no adulto considerado neoplasia maligna, pois tende à disseminação ${ }^{18}$, Um dos motivos para explicar esse comportamento é a freqüente relação com elementos precursores não teratomatosos, como o carcinoma embrionário.

Antigamente, o tratamento deste tumor era através da orquiectomia radical. Entretanto, atualmente, o testículo pode mostrar natureza cística da lesão, sugerindo teratoma, o que leva ao tratamento conservador, através de enucleação do cisto, com preservação do parênquima testicular e manutenção do seguimento rigoroso do paciente ${ }^{5,13}$.Haja vista que, raramente a malignização de teratoma testicular é reportada ${ }^{19}$.

\section{TUMOR DE CÉLULAS DE LEYDIG}

As neoplasias estromais de testículos englobam os tumores de células de Leydig, de células de Sertoli, os tumores da granulosa juvenil e os indiferenciados, que juntos somam um total de $10 \%$. Os tumores de células de Leydig, são os mais freqüentes entre os tumores não germinativos do testículo, têm sido descrito em todas as idades, mas com picos em crianças pré-púberes e adultos da $3^{\circ}$ e $4^{\circ}$ décadas. Ainda que, tradicionalmente seja descrito como tumor não relacionado com criptorquia prévia, tem-se descrito casos de associação da mesma, com a Síndrome de Klinefelter e com a esclerose tuberosa ${ }^{20}$. Seu diagnóstico é precoce pela aparição de sinais clínicos de puberdade, com aumento da genitália externa, pêlos pubianos, mudança da voz e agressividade, devida a produção exacerbada de testosterona. São universalmente considerados benignos nesta fase (infância), no entanto, cerca de $10 \%$ dos casos, e todos em adultos, são considerados malignos, sendo o único critério absoluto de malignidade é a presença de metástases ${ }^{21}$. Temse proposto uma série de achados morfológicos indicativos de malignidade, tais como: tumores grandes, presença de anaplasia celular, mitoses freqüentes ou atipia, margem infiltrante, necrose, invasão linfática e/ou de vasos sanguíneos, aneuploidia do DNA na citometria de fluxo, frente a diploidia nos tumores benignos. O tratamento é orquiectomia via inguinal, porém nos casos de suspeita, a biópsia intraoperatória é indicada, sobretudo, naqueles pacientes em que há algum comprometimento do testículo contra-lateral. Podese tentar a cirurgia conservadora, apesar da sua indicação não ser tão clara como nos teratomas e cistos epidermóides22,23. Estes tumores respondem mal à quimioterapia e à radioterapia. O seguimento deve ser periódico , com ultrassonografia do testículo contra-lateral e radiografia torácica realizados trimestralmente, a tomografia computadorizada (TC) deverá ser realizada no último controle trimestral e depois, anualmente ${ }^{24}$.

\section{TUMOR DE CÉLULAS DE SERTOLI}

Entre os tumores não germinativos de testículos, os tumores de células de Sertoli, é o segundo mais freqüente, são também conhecidos como androblastomas. É uma neoplasia metabolicamente inativa, portanto sem alterações endócrinas significativas, embora, em cerca de $14 \%$ dos pacientes encontra-se ginecomastia ${ }^{25}$. São detectados em períodos precoces da vida. Apesar da maioria destes tumores terem evolução benigna, há relatos de metástases, o que leva à indicação de orquiectomia radical, sendo suficiente na maioria dos $\operatorname{casos}^{2}{ }^{6}$, e no seguimento, a atenção deve estar no retroperitôneo. Os critérios de malignidade são semelhantes aos do tumor de células de Leydig, porém, diferente deste, há relato de comportamento maligno em crianças.

\section{CISTO EPIDERMÓIDE}

Na maioria dos estudos, o cisto epidermóide é tido como o quarto tumor em freqüência, em torno de $3 \%$ 
do total. O primeiro caso publicado foi em 1942. Define-se por ser um tumor, formado em quase sua totalidade por epitélio produtor de queratina, se diferencia do cisto dermóide, por não possuir anexos de pele a sua estrutura, como este, e do teratoma que possui em sua estrutura, os três folhetos embrionários. Assim como teratoma, o cisto epidermóide pré puberal pode ser considerado um tumor benigno. São detectados por auto exploração ao exame físico rotineiro, em $80 \%$ dos casos, podendo ser acompanhado de doenças testiculares prévias (20\%) ou antecedente de criptorquia em até $2 \%$ dos $\operatorname{casos}^{27}$. Price, estabeleceu cinco critérios para confirmação de lesão testicular por cisto epidermóide: cisto localizado de parênquima testicular; o centro do cisto está substituído por material amorfo ou restos queratinizados, a parede cística é um tecido fibroso, coberto parcial ou totalmente por tecido escamoso (Figura 4); não há elementos anexiais dérmicos ou teratomatosos dentro do cisto ou em algum lugar dentro do testículo; não observa-se cicatriz dentro do parênquima restante ${ }^{28}$. Ecograficamente são lesões bem delimitadas, com periferia hiperecogenica e ecogenicidade mista no centro $^{29,30}$. A ultrassonografia testicular é um exame extremamente útil para o planejamento cirúrgico, permitindo até mesmo a conservação testicular, sobretudo, em afecções bilaterais. A realização da cirurgia conservadora é uma opção a ser considerada, principalmente, quando há acometimento de ambos os testículos ${ }^{31}$, optando por biópsia de congelação, via exploração inguinal.

\section{RABDOMIOSARCOMA PARATESTICULAR}

É o terceiro tumor em frequência. Pela complexidade de seu manejo, requer tratamento individualizado e multidisciplinar. A Societé Internationale d'Oncologie Pediatrique (SIOP) recomenda a realização de orquiectomia radical via inguinal. $\mathrm{Na}$ abordagem via escrotal prévia é mandatória a realização de escrotectomia parcial. O tratamento adjuvante é realizado, seguindo protocolos, dependendo de análises anatomopatológicas da peça e estudos de extensão ${ }^{32,33}$. (Figura 5)

\section{CONSIDERAÇÕES FINAIS}

Os tumores testiculares na infância merecem uma atenção especial do ponto de vista terapêutico. A massa sólida testicular deve ser considerada maligna até que se prove o contrário. Existe uma tendência para realização de ressecções conservadoras para lesões de comportamento benigno tais como o teratoma, o tumor de células de Leydig e para o cisto epidermóide, desde que sejam confirmadas por biópsia de congelação.

A literatura sugere que a orquiectomia radical inguinal sem linfadenectomia retroperitoneal seja o procedimento mais correto para o tratamento de pacientes no estádio I. A linfadenectomia retroperitoneal, deverá ser empregada aos pacientes que se encontram nos estádios II e III. O tratamento cirúrgico após a violação escrotal é necessário e aumenta a taxa sobrevida. Não existem dúvidas que o tratamento padrão para os tumores testiculares é a ressecção. Porém a quimioterapia adjuvante nos tumores testiculares da infância ganha papel relevante na sobrevida de lesões mais avançadas.

É consenso que para o estadiamento I não há necessidade de complemento terapêutico cabendo somente o seguimento desses pacientes, vale lembrar que o estadiamento lé o mais freqüente com sobrevida em cinco anos em torno de $80 \%^{34}$.

Para àquelas no estádio II, III e as com recorrência do estádio l; a quimioterapia adjuvante com esquema padrão contendo bleomicina, etoposide e cisplatina (BEP) alcançam taxa de sobrevida de $87 \%, 72 \%$ e $100 \%$ respectivamente ${ }^{35}$.

Já para os tumores avançados com metástase o mesmo esquema de quimioterapia proporciona taxa de sobrevida de $56 \%$.

Temos então que a quimioterapia não é indicada para etadiamento I e para os demais estadiamentos o esquema BEP é efetivo, levando sempre em consideração que tratamento quimioterápico pode devido sua toxicidade levar a uma diminuição da função testicular e consequente infertilidade.

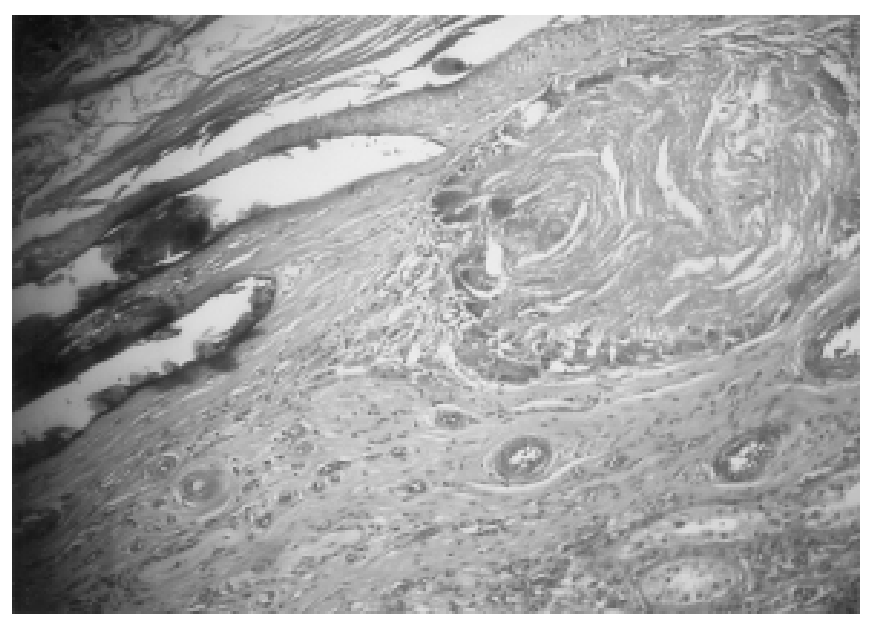

Figura 4 - Cisto Epidermóide com rotura e reação granulomatosa na parede, que apresenta intensa fibrose e calcificação distrófica.

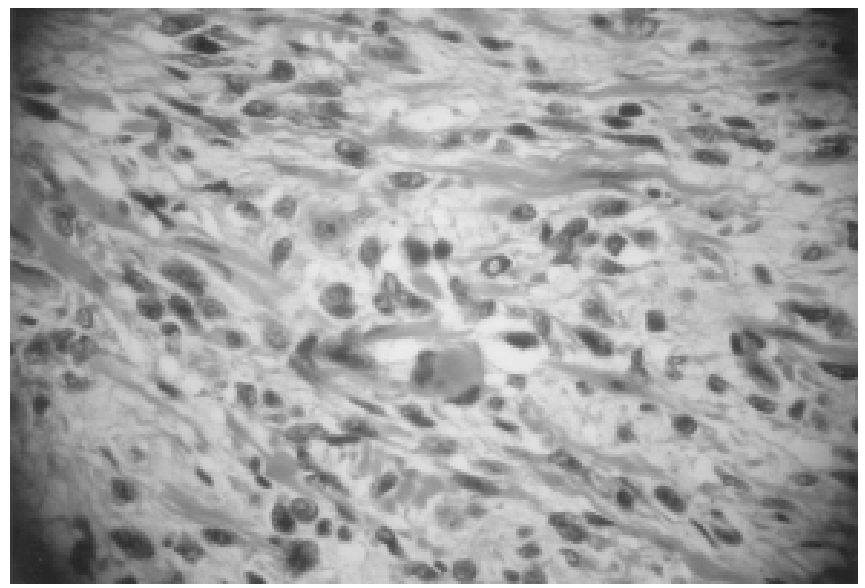

Figura 5 - Rabdomiosarcoma apresentando célula com aspecto de rabdomioblasto no centro. 


\section{A}

Testicular and paratesticular prepuberal tumors are rare. They represent around $1 \%$ of the total of tumors of infancy. They subdivide in 2 groups: germ cells tumors and non germ cells tumors, being able to occur in all the ages, and about $75 \%$ are malignant, and about $19 \%$ of these they present metastasis. The tumors of germ cells tumors represent $6075 \%$ of the tumors testiculars in infancy, having as main example the yolk sac tumor (65\% of the neoplasms), followed for teratomas (14\%); although some works to exist where teratoma, if presents as most common. The non germ cells tumors include the Leydig cell tumor and Sertoli cell tumor. The Leydig cell tumor, are most frequent between the non germ cells tumors testicular. This review article on epidemiology, diagnosis and treatment of to testicular and to paratesticular tumors in child.

Key words: Testicular neoplasms. Teratoma. Leydig cell tumor. Sertoli cell tumor. Children.

\section{REFERENCIAS}

1. Ciftci AO, Bingöl-Kologlu M, Senocak ME, Tanyel FC, Büyükpamukçu M, Büyükpamukçu N. Testicular tumors in children. J Pediatr Surg. 2001; 36(12):1796 -801.

2. Srougi M. Tumores do testículo na infância. In: Maksoud JG. Cirurgia pediátrica. $2^{a}$ ed. Rio de Janeiro: Revinter; 2003. p.1135-42.

3. Sugita Y, Clarnette TD, Cooke-Yarborough C, Chow CW, Waters $\mathrm{K}$, Hutson JM. Testicular and paratesticular tumors in children: 30 years' experience. Aust N Z J Surg. 1999; 69(7):505-8.

4. Oottamasathien S, Thomas JC, Adams MC, DeMarco RT, Brock JW 3rd, Pope JC 4th. Testicular tumours in children: a singleinstitutional experience. BJU Int. 2007; 99(5):1123-6.

5. Cologna A J, Martins ACP, Tucci Jr S, Suaid HJ, Celini FM, Paschoal RM, Paschoalin EL. Tumores testiculares na infância. Acta Cir Bras. 2003; 18(5):52:4

6. Llinares Riestra E, Fuster Soler JL, Alarcón Martínez H, López Cubillana P, Pérez Albacete M, Cao Avellaneda E. Tumores testiculares y paratesticulares prepuberales. Experiencia en nuestro centro y revisón de la literatura. Actas Urol Esp. 2005; 29(4):355-9

7. Figueiredo TMS, Billis A. Tumor do saco vitelino testicular: estudo microscópico de 15 casos. J Bras Patol. 2000; 36(3):185-90.

8. $\mathrm{Xu} H \mathrm{HX}, \mathrm{Yi} \mathrm{XP}$. Sonographic appearance of a testicular yolk sac tumor in a 2-year-old boy. J Clin Ultrasound. 2007; 35(1):55-7.

9. Walsh TJ, Grady RW, Porter MP, Lin DW, Weiss NS. Incidence of testicular germ cell cancers in U.S. children: SEER program experience 1973 to 2000. Urology. 2006; 68(2):402-5; discussion 405

10. Mottet N, Berger N, Droz JP. [Diagnosis and staging of germ-cell tumours of the testis]. Rev Prat. 2007; 57(4):365-78.

11. Tucci Jr S, Tone LG, Molina CAF, Suaid HJ, Peres LC, Chammas Jr MF, Cologna AJ, Martins ACP. Tumores testiculares e paratesticulares na infância. Acta Cir Bras. 2000; 15(2):57-9.

12. Castellino SM, McLean TW. Pediatric genitourinary tumors. Curr Opin Oncol. 2007; 19(3):248-53

13. Walsh C, Rushton HG. Diagnosis and management of teratomas and epidermoid cysts. Urol Clin North Am. 2000; 27(3):509 -18.

14. Grady R, Ross JH, Kay R. Epidemiological features of testicular teratoma in a prepubertal population. J Urol. 1997; 158(3 Pt 2):1191-2.

15. Khoury A, Hesam FM, Bagil DD. Prepubertal testicular and paratesticular tumors. J Urol. 1996; 155:392.

16. Marshall S, Lyon RP, Scott MP. A conservative approach to testicular tumors in children: 12 cases and their management. J Urol. 1983; 129(2):350.

17. Lo Curto M, D'Angelo P, Cecchetto G, Klersy C, Dall'Igna P, Federico $A$, et al. Mature and immature teratomas: results of the first paediatric Italian study. Pediatric Surg Int. 2007; 23(4):315-22. Epub 2007 Feb 28

18. Ulbright TM. Gonadal teratomas: a review and speculation. Adv Anat Pathol. 2004; 11(1):10-23.

19. Koseoglu RD, Parlaktas BS, Filiz NO, Erdemir F, Uluocak N, Tulunay $\mathrm{O}$. Adenocarcinoma originating from a mature teratoma of the testis. Kaohsiung J Med Sci. 2007; 23(5):265-8.

20. Kirsh AJ, Bastian W, Cohen HL, Glassberg KI. Precocious puberty in a child with unilateral Leydig cell tumor of the testis following orchiopexy. J Urol. 1993; 150(5 Pt 1):1483-5.
21. Richie JP. Neoplasias testiculares. Walssh PC, Retik A, Vaughan D, Wein A, editors. Campbell's Urologia. Barcelona: Editorial Médica Panamericana; 1994. p. 1220-62.

22. Velázquez MAR, Schaan JIDV, García BM, Rodríguez RH, Martín JAP, Gómez MAC, Baños JLG, Edreira AR, Castrillo AH, Bernal JFV, Blázquez JP. Tumor de células de Leydig. Aportación de dos casos y revisión de la literatura. Actas Urol Esp. 2001; 25(5):371-6.

23. Merlini E, Seymandi PL, Betta PG, Bussi G. Testis sparing enucleation of a Leydig-cell tumour in a boy. Pediatr Med Chir. 2003; 25(1):63-5.

24. Guanter VR, Durba AS, Armada Jr B, Bon Beneto F, Lence JCP, Laorden CS. Tumores de células de Leydig: presentación de dos casos. Actas Urol Esp. 1999; 23(2):270-2.

25. Garbrilove JL, Freiberg EK, Leiter E, Nicolis GL. Feminizing and nonfeminizing Sertoli cell tumors. J Urol. 1980; 124(6):757-67.

26. Young RH, Koelliker DD, Scully RE. Sertoli cell tumors of the testis, not otherwise specified: a clinicopathologic analysis of 60 cases. Am J Surg Pathol. 1998; 22(6):709-21.

27. Mármol Navarro S, Leva Valejjo M, Leal Arenas J, Ortega Bevia C, Hierro Guilmain C. Quiste epidermoide testicular. Arch Esp Urol.1998; 51(10):1039-41.

28. Price EB Jr. Epidermoid cyst of the testis: a clinical and pathological analysis of 69 cases from the testicular tumor registry. J Urol. 1969; 102(6):708-13.

29. Davi RC, Braslis KG, Pérez JL, Soloway MS. Bilateral epidermoid cysts of the testis. Eur Urol. 1996; 29(1):122-4

30. Bahnson RR, Slasky BS, Ernstoff MS, Banner BF. Sonographic characteristics of epidermoid cyst of testicle. Urology. 1990; 35(6):508-10

31. Walsh C, Rushton H. Diagnosis and management of a teratomas and epidermoid cysts. Urol Clin North Am. 2000; 27(3):509-18.

32. Crist WM, Anderson JR, Meza JL, Fryer C, Raney RB, Ruymann FB, et al . Intergroup rhabdomyosarcoma study-IV: results for patients with nonmetastasic disease. J Clin Oncol. 2001; 198(12):3091-102.

33. Kaefer M, Rink RC. Genitourinary rhabdomyosarcoma.Treatment options. Urol Clin North Am. 2000; 27(3):471-87.

34. Schalatter M, Rescorla F, Giller R, Cushing B, Vinocur C, Colombani $P$, et al. Excellent outcome in patients with stage I germ cell tumors of the testes: a study of the Children's Cancer Group/Pediatric Oncology Group. J Pediatr Surg. 2003; 38(3):319-24.

35. Hass RJ, Schimdt P, Göbel U, harms D. Treatment of malignant testicular tumors in childhood: results of the German National Study 1982-1992. Med Pediatr Oncol. 1994; 23(5):400-5.

Recebido em 16/04/2008

Aceito para publicação 20/06/2008

Conflito de interesse: nenhum

Fonte de financiamento: nenhuma

\section{Como citar este artigo:}

Teixeira RL, Rossini A, Paim NF. Tumores testiculares na infância. Rev Col Bras Cir. [periódico na Internet] 2009; 36(1). Disponível em URL: http://www.scielo.br/rcbc

\section{Endereço para correspondência:}

Roni Leonardo Teixeira

Email: ronileonardo@zipmail.com.br 